\title{
Research \\ Near-infrared spectroscopy technique to evaluate the effects of red blood cell transfusion on tissue oxygenation
}

\author{
Jacques Creteur, Ana Paula Neves and Jean-Louis Vincent
}

Department of Intensive Care, Erasme University Hospital, Université Libre de Bruxelles, Route de Lennik 808, 1070 Brussels, Belgium

Corresponding author: Dr Jean-Louis Vincent, jlvincen@ulb.ac.be

Published: 30 November 2009

This article is online at http://ccforum.com/content/13/S5/S11

(c) 2009 BioMed Central Ltd
Critical Care 2009, 13(Suppl 5):S11 (doi:10.1186/cc8009)

\section{Introduction}

Critically ill patients often receive red blood cell (RBC) transfusions. Studies conducted in Europe and the United States have reported that RBC transfusions were administered to approximately $40 \%$ of all patients [1,2], with an average of almost 5 units of RBCs per patient; this has changed little over the past decade [3]. Some 40 to $80 \%$ of RBC transfusions in the intensive care unit (ICU) are not administered for hemorrhage, but for low hemoglobin levels, for a decrease in physiological reserve, or for alterations in tissue perfusion [2].

Few clinical techniques can directly monitor tissue oxygen levels or quantify tissue oxygen consumption $\left(\mathrm{VO}_{2}\right)$. The presence of tissue hypoxia and how much transfusion is necessary to correct the oxygen deficit are therefore still hard to determine. It is even difficult to say whether RBC transfusion really improves tissue oxygenation. In pathological inflammatory conditions, such as sepsis or during the postoperative period, systemic oxygenation variables do not necessarily reflect local tissue oxygenation because of mechanisms such as shunting or vascular dysregulation [4]. Clinical studies on the efficacy of RBC transfusion have used different endpoints for tissue oxygenation, including systemic $\mathrm{VO}_{2}$, blood lactate, and base excess levels $[5,6]$. A few studies have demonstrated an improvement in tissue oxygenation after RBC transfusion associated with an increase in oxygen delivery $\left(\mathrm{DO}_{2}\right)$; other studies have not $[7,8]$. More general and indirect survival measures, such as mortality, morbidity, or length of hospital stay [1,9-11], are prone to confounding and are difficult to influence [9].

Near-infrared spectroscopy (NIRS) has recently emerged as a valuable tool for monitoring peripheral oxygenation in various tissues, including the muscle. By performing a vasoocclusive test, a variety of NIRS-derived variables can be

$\Delta \mathrm{NIR} \mathrm{VO}_{2}=$ difference between muscle oxygen consumption values after and before transfusion; $\Delta \mathrm{StO}_{2}=$ difference between thenar tissue oxygen saturation upslopes after and before transfusion; $\mathrm{DO}_{2}=$ oxygen delivery; ICU = intensive care unit; NIR = near-infrared; NIRS = near-infrared spectroscopy; $\mathrm{RBC}=$ red blood cell; $\mathrm{StO}_{2}=$ thenar tissue oxygen saturation; $\mathrm{THI}=$ tissue hemoglobin index; $\mathrm{VO}_{2}=$ oxygen consumption. 
measured to assess, in particular, tissue $\mathrm{VO}_{2}$ and microvascular reactivity [12].

The aim of the present study was to evaluate the effects of $\mathrm{RBC}$ transfusions on muscle tissue oxygenation, $\mathrm{VO}_{2}$ and microvascular reactivity in critically ill patients using the NIRS technology.

\section{Materials and methods}

After approval by the ethical committee of Erasme Hospital, informed consent was obtained from each patient's next of kin. This prospective study enrolled consecutive patients hospitalized in the 31-bed Department of Intensive Care Medicine of Erasme Hospital with anemia requiring $\mathrm{RBC}$ transfusion. The indication for RBC transfusion was a hemoglobin concentration either $<8 \mathrm{~g} / \mathrm{dl}$ or between 8 and $9 \mathrm{~g} / \mathrm{dl}$ in the presence of altered tissue perfusion (that is, elevated lactate levels) or coronary artery syndromes. Exclusion criteria were RBC transfusion in the preceding 72 hours, peripheral vascular disease, liver cirrhosis, age $<18$ years, active bleeding, and pregnancy. Hemodynamic and NIRSderived variables were obtained immediately before (baseline) and 1 hour after transfusion of 1 unit packed RBCs. During the study period, no bedside procedures were performed, doses of vasopressor and sedative agents were kept constant, and the patient's position was not changed.

\section{Red blood cell transfusion characteristics}

Packed RBC units were obtained from the blood bank of Erasme Hospital, and were supplied by the Belgian Red Cross. All RBC units transfused in ICU patients in our hospital have undergone leukoreduction by filtration before storage in a saline-adenine-glucose-mannitol solution. The storage period can be extended up to 42 days, and there is no blood bank policy to preferentially transfuse fresh RBCs.

\section{Measurements}

The temperature, heart rate, arterial pressure, and central venous pressure were recorded in all patients before and 1 hour after transfusion. In addition, complete hemodynamic measurements were obtained in 14 patients who were monitored with a pulmonary artery catheter. Arterial and central venous or mixed venous blood samples were withdrawn simultaneously, and blood gases, hemoglobin saturation, and hemoglobin and lactate concentrations were measured before and 1 hour after transfusion (ABL700; Radiometer, Copenhagen, Denmark). The $\mathrm{DO}_{2}, \mathrm{VO}_{2}$ and oxygen extraction ratio were calculated using standard formulas [13]. The Acute Physiology and Chronic Health Evaluation II score [14] was obtained at admission, and the Sequential Organ Failure Assessment score [15] was obtained on the study day. The length of RBC storage before transfusion was noted in each case.

\section{NIRS measurements and analysis}

The thenar tissue oxygen saturation $\left(\mathrm{StO}_{2}\right)$ and the tissue hemoglobin index (THI), an indicator of the blood volume in the region of the microvasculature sensed by the NIRS probe $[16,17]$, were measured using a tissue spectrometer (InSpectra $^{\text {TM }}$ Model 325; Hutchinson Technology Inc., Hutchinson, MN, USA), which uses reflectance mode probes to measure scattered light reflected at some distance from where the light is transmitted into the tissue. The maximum depth of the tissue sample was estimated as one-half of the distance between the probe's sending and receiving fibers (probe spacing); we used a probe spacing of $25 \mathrm{~mm}$. A lightscattering calibrator was used to normalize the tissue spectrometer during startup of the system and before each measurement. Sample measurement signals were updated every 3.5 seconds.

When the patient was hemodynamically stable (mean arterial pressure $>65 \mathrm{mmHg}$ and no change in vasopressor doses for 2 hours), the NIRS probe was placed on the skin of the thenar eminence and a sphygmomanometer cuff was wrapped around the arm over the brachial artery. After a 3-minute period necessary to stabilize the $\mathrm{StO}_{2}$ signal, arterial inflow was stopped by inflation of the cuff to $50 \mathrm{mmHg}$ above the systolic arterial pressure. After 3 minutes of ischemia the cuff pressure was released, and $\mathrm{StO}_{2}$ was continuously recorded for another 3 minutes (reperfusion period). We measured the $\mathrm{StO}_{2}$ and $\mathrm{THI}$ continuously during the vaso-occlusive test, and recorded the baseline $\mathrm{StO}_{2}$ and THI before the ischemic period and the THI after 1 minute of occlusion. During occlusion, we calculated the $\mathrm{StO}_{2}$ desaturation slope (\%/minute) obtained by the regression line of the first minute of $\mathrm{StO}_{2}$ decay after occlusion [16]. During the reperfusion phase, we calculated the $\mathrm{StO}_{2}$ upslope of the reperfusion phase (\%/second) obtained by the regression line of the first 14 seconds of increased $\mathrm{StO}_{2}$ (five $\mathrm{StO}_{2}$ values) following the ischemic period. This $\mathrm{StO}_{2}$ upslope of the reperfusion phase was used to quantify the intensity of the reactive hyperemic response following release of the occluding cuff. The $\Delta \mathrm{StO}_{2}$ upslope of the reperfusion phase was calculated as the difference between the $\mathrm{StO}_{2}$ upslopes of the reperfusion phase after and before transfusion. Muscle oxygen consumption (NIR $\mathrm{VO}_{2}$ ) was calculated as the product of the inverse value of the $\mathrm{StO}_{2}$ desaturation slope and the mean $\mathrm{THI}$ over the first minute of arterial occlusion [16], and is expressed in arbitrary units:

$$
\begin{gathered}
\mathrm{NIR} \mathrm{VO} \\
\mathrm{VO}_{2}=\left(\mathrm{StO}_{2}\right. \text { desaturation slope } \\
\left(\mathrm{THI}_{\text {start cuff }}+\mathrm{THI}_{1 \mathrm{~min}}\right) \times / 2
\end{gathered}
$$

$\triangle \mathrm{NIR} \mathrm{VO}_{2}$ (arbitrary units) was calculated as the difference between the $\mathrm{NIR} \mathrm{VO}_{2}$ values after and before transfusion.

\section{Statistical analysis}

Descriptive statistics were computed for all study variables. The Kolmogorov-Smirnov test was used to verify the 
Table 1

\section{Characteristics of the study group ( $n=44$ patients)}

Age (years)

Gender, male

65 (57 to 73 )

$29(66)$

Body mass index

26 (23 to 27 )

Acute Physiology and Chronic Health

15 (11 to 18 )

Evaluation II score

Sequential Organ Failure Assessment score

6 (4 to 8 )

Medical diagnosis

$24(54.5)$

Sepsis

18 (40.9)

Intensive care unit length of stay (days)

10 (5 to 28$)$

Outcome, intensive care unit death

Vasopressor support

17 (38.6)

$15(34.1)$

$6(13.6)$

Renal replacement therapy

18 (11 to 27$)$

Red blood cell storage time (days)

Data are presented as median (25th to 75 th percentiles) or $n$ (\%).

normality of distribution of continuous variables. Wilcoxon's test was used to compare the baseline and post-transfusion values. The relationship between NIRS-derived variables was assessed by Spearman rank correlation. Data were analyzed using SPSS 12.0 for Windows (SPSS, Chicago, IL, USA). The level of statistical significance was 0.05. Data are presented as the median (25th to 75 th percentiles).

\section{Results}

The study included 44 hemodynamically stable patients, 18 of whom had sepsis (Table 1). The median ICU length of stay was 10 (5 to 28 ) days, and the 28 -day mortality was $27 \%$ (Table 1). No transfusion-related adverse reaction was observed during the study. Blood transfusion resulted in increases in hemoglobin concentration (from 7.1 (6.7 to 7.7) to 8.4 (7.1 to 9$) \mathrm{g} / \mathrm{dl} ; P<0.01$ ) and in $\mathrm{DO}_{2}$ (from 306 (259 to 337 ) to 356 (332 to 422 ) $\mathrm{ml} / \mathrm{minute}^{2} \mathrm{~m}^{2} ; P<0.001$ ). The mean arterial pressure also increased (from 76 (70 to 83 ) to 80 (74 to 93) $\mathrm{mmHg} ; P<0.01$ ) (Table 2). Systemic $\mathrm{VO}_{2}$ and NIRS-derived variables, however, were unaltered by transfusion (Table 2).

Although RBC transfusion globally failed to affect NIRSderived variables (Table 2), there was considerable interindividual variation, with improvement in some patients and deterioration in others. The $\Delta \mathrm{StO}_{2}$ upslope of the reperfusion phase was negatively correlated to the baseline $\mathrm{StO}_{2}$ upslope of the reperfusion phase $\left(r^{2}=0.42 ; P<0.0001\right)$ (Figure 1). This negative correlation was present in septic patients $\left(r^{2}=0.46 ; P=0.0044\right)$ and in nonseptic patients $\left(r^{2}=0.41 ; P=0.0027\right)$. $\Delta \mathrm{NIR} \mathrm{VO}_{2}$ was also negatively correlated to baseline NIR $\mathrm{VO}_{2}\left(r^{2}=0.48 ; P=0.0015\right)$ (Figure 2). This latter correlation was present in septic
Figure 1

Delta $\mathrm{StO}_{2}$ upslope of the reperfusion phase (\%/sec)

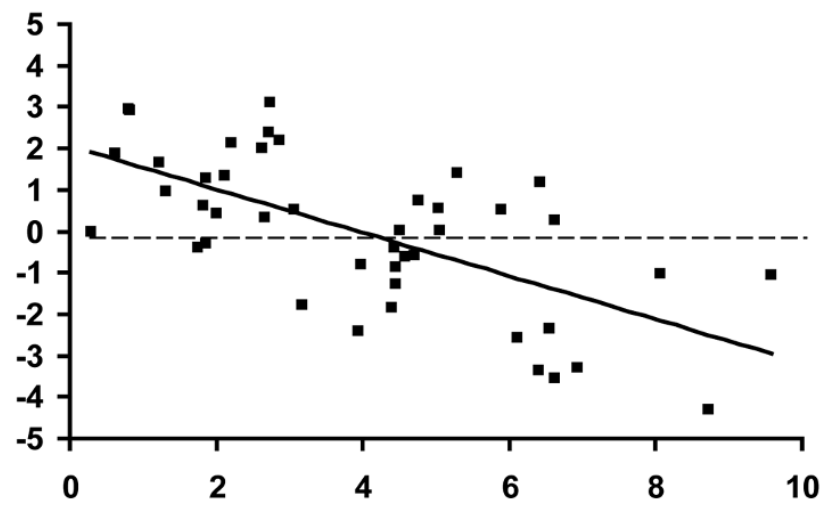

Baseline $\mathrm{StO}_{2}$ upslope of the reperfusion phase (\%/sec)

Relationship between baseline and change in thenar tissue oxygen saturation reperfusion phase upslopes. $x$ axis: Baseline thenar tissue oxygen saturation $\left(\mathrm{StO}_{2}\right)$ upslope of the reperfusion phase

(\%/second); $y$ axis: the difference between the $\mathrm{StO}_{2}$ upslopes of the reperfusion phase after and before transfusion (\%/second). $r^{2}=0.42$; $P<0.0001$

\section{Figure 2}

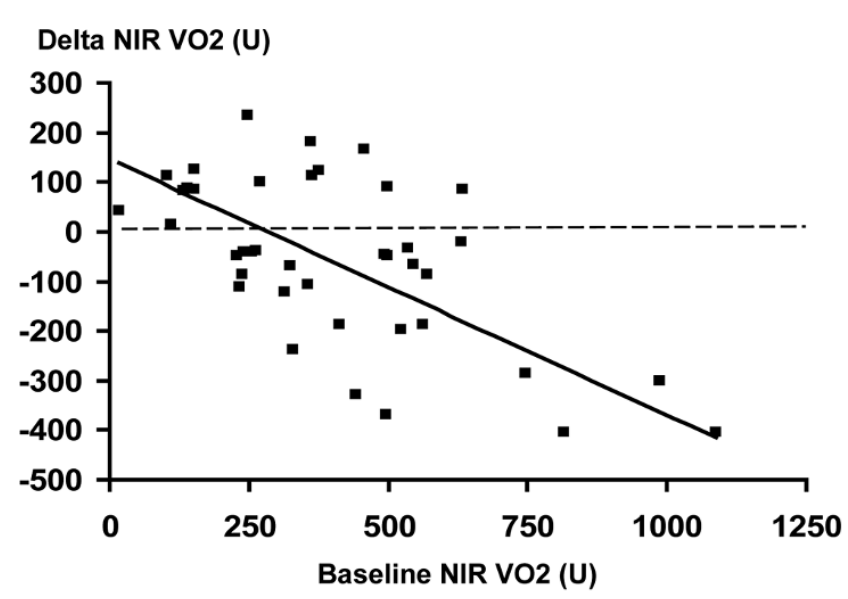

Relationship between baseline muscle oxygen consumption and change in muscle oxygen consumption. $x$ axis: baseline muscle oxygen consumption (NIR $\mathrm{VO}_{2}$; arbitrary units); $y$ axis: difference in $\mathrm{NIR} \mathrm{VO}_{2}$ after and before transfusion ( $\triangle \mathrm{NIR} \mathrm{VO}_{2}$; arbitrary units). $\mathrm{NIR} \mathrm{VO}_{2}$ was calculated as the product of the inverse value of the thenar tissue oxygen saturation $\left(\mathrm{StO}_{2}\right)$ desaturation slope and the mean tissue hemoglobin index over the first minute of arterial occlusion. $r^{2}=0.48$; $P=0.0015$.

patients $\left(r^{2}=0.56 ; P<0.018\right)$ and in nonseptic patients $\left(r^{2}=0.32 ; P=0.04\right) . \Delta \mathrm{NIR} \mathrm{VO}_{2}$ was weakly but significantly related to the $\Delta \mathrm{StO}_{2}$ upslope of the reperfusion phase $\left(r^{2}=0.14 ; P=0.038\right)$. There was no correlation between baseline physiologic variables or RBC storage time and the $\Delta \mathrm{StO}_{2}$ upslope of the reperfusion phase slope or $\Delta \mathrm{NIR} \mathrm{VO} \mathrm{V}_{2}$. 
Table 2

Physiologic and near-infrared spectroscopy-derived variables before and 1 hour after red blood cell transfusion

\begin{tabular}{|c|c|c|}
\hline Variable & Baseline & After transfusion \\
\hline Temperature $\left({ }^{\circ} \mathrm{C}\right)$ & $36.8(36.2$ to 37.5$)$ & 37 (36.4 to 37.7 ) \\
\hline Heart rate (beats/minute) & $94(78$ to 114$)$ & 94 (77 to 115$)$ \\
\hline Mean arterial pressure $(\mathrm{mmHg})$ & 76 (70 to 83 ) & $80(74 \text { to } 93)^{*}$ \\
\hline Central venous pressure $(\mathrm{mmHg})$ & 12 (9 to 16$)$ & 12 (9 to 16$)$ \\
\hline Mean pulmonary artery pressure $(\mathrm{mmHg})^{a}$ & 29 (27 to 33 ) & 30 (26 to 39$)$ \\
\hline Pulmonary artery occlusion pressure $(\mathrm{mmHg})^{a}$ & 17 (15 to 18$)$ & $19(14$ to 19$)$ \\
\hline Cardiac index $\left(1 / \text { minute } / \mathrm{m}^{2}\right)^{\mathrm{a}}$ & $3.0(2.7$ to 3.4$)$ & $3.1(2.9$ to 3.4$)$ \\
\hline Hemoglobin concentration (g/dl) & $7.1(6.7$ to 7.7$)$ & $8.4(7.1 \text { to } 9)^{*}$ \\
\hline Arterial partial pressure of carbon dioxide $(\mathrm{mmHg})$ & 35 (32 to 37 ) & 35 (31 to 38 ) \\
\hline Arterial partial pressure of oxygen $(\mathrm{mmHg})$ & 94 (85 to 109$)$ & 93 (84 to 113 ) \\
\hline $\mathrm{pH}$ & 7.45 (7.39 to 7.48$)$ & 7.44 (7.4 to 7.5$)$ \\
\hline $\mathrm{SaO}_{2}(\%)$ & 99 (98 to 99$)$ & 99 (98 to 99$)$ \\
\hline Lactate $(\mathrm{mmol} / \mathrm{l})$ & $1.2(0.9$ to 2.2$)$ & $1.3(0.8$ to 2.1$)$ \\
\hline Mixed venous oxygen saturation (\%)a & 65 (51 to 72$)$ & 70 (52 to 74$)$ \\
\hline Oxygen delivery $\left(\mathrm{ml} / \text { minute } / \mathrm{m}^{2}\right)^{\mathrm{a}}$ & 306 (259 to 337 ) & $356(332 \text { to } 422)^{*}$ \\
\hline Oxygen consumption $\left(\mathrm{ml} / \mathrm{minute} / \mathrm{m}^{2}\right)^{\mathrm{a}}$ & $116(85$ to 142$)$ & 118 (97 to 168$)$ \\
\hline Oxygen extraction ratio (\%)a & 34 (28 to 48$)$ & $28(24$ to 46$)$ \\
\hline Thenar tissue oxygen saturation (\%) & 90 (81 to 94$)$ & $90(80$ to 94$)$ \\
\hline Tissue hemoglobin index (arbitrary units) & $14(13$ to 17$)$ & $13(11$ to 18$)$ \\
\hline Inverse thenar tissue oxygen desaturation slope (\%/minute) & 22 (17 to 35$)$ & 21 (16 to 32$)$ \\
\hline Thenar tissue oxygen saturation upslope of the reperfusion phase (\%/second) & $4.1(2.1$ to 5.4$)$ & $3.8(2.9$ to 5.1$)$ \\
\hline Muscle oxygen consumption (arbitrary units) & 363 (240 to 536$)$ & 373 (215 to 500$)$ \\
\hline
\end{tabular}

Data are presented as median (25th to 75th percentiles). ${ }^{a}$ Measurements obtained in 14 patients equipped with a pulmonary artery catheter. ${ }^{\star} P<0.05$ versus baseline.

\section{Discussion}

The main finding of our study was that RBC transfusion had no consistent effect on muscle $\mathrm{StO}_{2}, \mathrm{VO}_{2}$, or microvascular reactivity in critically ill patients. There was, however, considerable interindividual variability. Importantly, there was a divergent response, with an improvement in microvascular reactivity in patients with altered microvascular reactivity at baseline and a deterioration in microvascular reactivity in patients with preserved baseline microvascular reactivity. The same effect was observed for NIR VO $\mathrm{V}_{2}$. The changes in NIRS derived-variables were not related to the RBC storage time.

The effects of blood transfusions on the microcirculation and tissue oxygenation are still poorly defined, especially in critically ill patients. Sakr and colleagues [18] studied the effects of RBC transfusion on the sublingual microcirculation assessed by the orthogonal polarization spectral technique in patients with severe sepsis. As in the present study, the authors reported that $\mathrm{RBC}$ transfusion had no consistent effect on sublingual microvascular perfusion in these septic patients [18]. There was again considerable interindividual variability in the response to RBC transfusions, with an improvement in sublingual microvascular perfusion in patients with altered perfusion at baseline and a deterioration in sublingual microvascular perfusion in patients with preserved baseline perfusion; these data are highly consistent with our results.

The critical question is why some patients show beneficial effects of RBC transfusions while others do not. Oxygenation of the microcirculation is the result of a close interplay between RBCs and microcirculatory vessels. If transfusion does not improve tissue oxygenation, this could be related to the condition of the microcirculation in the patient or to the RBCs. Endogenous RBC deformability may be an important factor. Indeed, RBC rheology is altered in various diseases, including acute conditions - such as ICU patients with sepsis or with an inflammatory reaction due to postoperative states 
or intracerebral hemorrhage - or chronic conditions - such as diabetes mellitus or terminal renal failure [19]. Friedlander and colleagues [20] observed that RBC transfusions improved RBC deformability in patients with sepsis, probably by replacing rigid, endogenous RBCs by more functional, or less dysfunctional, exogenous RBCs.

RBC storage may also be an important factor in determining individual response to transfusion. Alterations in RBCs during storage include a reduction in RBC deformability [21], altered adhesiveness and aggregability, and a reduction in 2,3diphosphoglycerate and ATP levels [22]. These findings were challenged by Raat and colleagues [23], however, who reported that storage of rat RBCs for up to 5 weeks did not alter their deformability or their oxygen-carrying properties. A recent literature review reported no strong association between duration of storage and complications [24]. A small clinical study suggested an adverse effect of RBC storage on intramucosal $\mathrm{pH}$ [5], but other studies failed to confirm these findings $[6,25]$. In a prospective, observational trial in patients with severe traumatic brain injury [26], transfusion of RBCs increased cerebral oxygenation, except in patients transfused with RBCs that had been stored for more than 19 days. The median RBC storage time in our study was 18 days, as in other studies $[2,27]$, and there was no relationship between the changes in NIRS-derived variables after transfusion and $\mathrm{RBC}$ storage time.

Reactive hyperemia can be considered an integral test of microcirculatory reactivity [28], evaluating the tissue's ability to adjust oxygen extraction capabilities to $\mathrm{DO}_{2}$ after a hypoxic stimulus induced by a transient interruption of blood flow. This process is complex, involving capillaries, arterioles, and small arteries, increasing flow in previously patent capillaries and recruiting additional capillaries. Hypoxic stimuli induce dilation of precapillary arterioles, favoring the opening of closed capillaries (recruitment) and increasing blood flow in previously patent capillaries - a phenomenon called reactive hyperemia. Alterations in the microcirculation have been reported in patients with sepsis [29] and in patients with inflammatory reactions due to postoperative states or other diseases [30,31]. These alterations are typically characterized by a decrease in microvascular density and an increase in the heterogeneity of microvascular blood flow, with an increase in intermittent or stopped flow capillaries, which could limit the number of recruitable capillaries after a hypoxic stimulus and thus alter the reactive hyperemia phenomenon [32].

The mechanisms that control the microvascular distribution of capillary blood flow under hypoxic conditions are not completely understood. The endothelium seems to play a central role both as an oxygen sensor [33] and by inducing vasodilatation [34] by releasing nitric oxide $[33,35,36]$. The $\mathrm{K}_{\text {ATP }}$ channels in the vascular smooth muscle also play a significant role in matching oxygen supply to demand during ischemia [37]. In addition to their role as microcirculatory components, RBCs are now considered primordial actors in the delivery of oxygen, rather than just being oxygen transporters. Indeed, RBCs can use hemoglobin not only as an oxygen carrier but also as an oxygen sensor, which can modulate tissue oxygen flow variables - by the release of the vasodilators, nitric oxide [38,39] or ATP [40]. This release of vasodilators from RBCs during hypoxia could be impaired during storage. The transfusion of stored RBCs could therefore affect microvascular reactivity to hypoxia in patients who have preserved microvascular reactivity before transfusion.

Transfusions may therefore be deleterious when performed in patients with preserved deformability and/or vasoreactivity but may be favorable when performed in patients with markedly altered RBC deformability and/or vasoreactivity. These findings may explain why RBC transfusion decreased microvascular reactivity and $\mathrm{NIR} \mathrm{VO}_{2}$ when these were essentially normal at baseline but improved these variables when they were already decreased at baseline. Interestingly, $\mathrm{RBC}$ transfusion-induced changes in the $\mathrm{StO}_{2}$ upslope of the reperfusion phase were related to changes in $\mathrm{NIR} \mathrm{VO}_{2}$, suggesting that an improvement in microvascular reactivity (and perhaps an improvement in microvascular blood flow) is associated with an increase in local muscle $\mathrm{VO}_{2}$.

Although there was considerable interindividual variability, globally $\mathrm{StO}_{2}$ was not altered by RBC transfusion. There was no relationship between baseline $\mathrm{StO}_{2}$ and the change in $\mathrm{StO}_{2}$ after RBC transfusion. Nevertheless, the present study was performed in hemodynamically stable patients, sometimes several days after their ICU admission. Baseline $\mathrm{StO}_{2}$ values were also in the normal range [41]. RBC transfusion may have different effects on $\mathrm{StO}_{2}$ if given in the early phase of resuscitation.

The THI was not altered by RBC transfusion. It is well known that hematocrit is lower in the capillaries than in large arteries and veins as a result of heterogeneous flow distribution, the Fahraeus effect, and interactions between a luminal glycocalyx and plasma macromolecules [42-44]. In this context, increasing the systemic hematocrit by RBC transfusion has only limited effects on the microvascular hematocrit. Using NIRS technology, Doerschug and colleagues showed that the THI was not related to blood hemoglobin concentration in patients with severe sepsis [45].

Our study has some limitations. First, the NIRS technology itself has some limitations. $\mathrm{StO}_{2}$ represents the average of the hemoglobin oxygen saturation in arterioles, venules, and capillaries in the measured volume of tissue, and the relative contributions of arterial, venous, and capillary blood within the measured volume of tissue cannot be determined. NIRS does not measure microcirculatory blood flow, and therefore the increase in $\mathrm{StO}_{2}$ after temporary arterial occlusion does not necessarily reflect the local increase in $\mathrm{DO}_{2}$ characterizing 
the reactive hyperemic response. Furthermore, measurements are influenced by adipose tissue thickness [46] - the thenar eminence is therefore usually selected for NIRS studies because the thickness of the adipose tissue covering this muscle is less influenced by the body mass index. Second, our measurements were restricted to 1 hour after RBC transfusion, so we may have missed alterations that occurred later. Our study already lasted for a total of about 2 hours (including the time needed for RBC transfusion), however, and longer follow-up periods are practically difficult because of inevitable changes in therapy and procedures. In addition, spontaneous changes in the patient's condition may influence microcirculatory perfusion and tissue oxygenation. Nevertheless, changes in the microcirculation are expected to occur early after the RBC transfusion, so it is unlikely that extending the study period would have altered our conclusions.

\section{Conclusion}

The effects of RBC transfusions on muscle oxygenation and microvascular reactivity are quite variable and are dependent on some baseline NIRS-derived variables. These effects cannot be predicted from systemic hemodynamics, biological variables, or disease severity, and are also independent of the age of the transfused RBCs. Although further studies are needed, the NIRS technique may represent a valuable tool to help evaluate the effects of RBC transfusions in acutely ill patients.

\section{Competing interests}

JC has received payment from Hutchinson for lectures. The Department of Intensive Care, Erasme Hospital has received some free devices from Hutchinson for study purposes.

\section{Acknowledgement}

This article is part of Critical Care Volume 13 Supplement 5: Tissue oxygenation $\left(\mathrm{StO}_{2}\right)$ in healthy volunteers and critically-ill patients. The full contents of the supplement are available online at http://ccforum. com/supplements/13/S5. Publication of the supplement has been supported with funding from Hutchinson Technology Inc.

\section{References}

1. Vincent JL, Baron JF, Reinhart K, Gattinoni L, Thijs L, Webb A, Meier-Hellmann A, Nollet G, Peres-Bota D: Anemia and blood transfusion in critically ill patients. JAMA 2002, 288:14991507.

2. Corwin HL, Gettinger A, Pearl RG, Fink MP, Levy MM, Abraham E, Macintyre NR, Shabot MM, Duh MS, Shapiro MJ: The CRIT Study: anemia and blood transfusion in the critically ill current clinical practice in the United States. Crit Care Med 2004, 32:39-52.

3. Corwin HL, Parsonnet KC, Gettinger A: RBC transfusion in the ICU. Is there a reason? Chest 1995, 108:767-771.

4. Ince C: The microcirculation is the motor of sepsis. Crit Care 2005, 9(Suppl 4):S13-S19.

5. Marik PE, Sibbald WJ: Effect of stored-blood transfusion on oxygen delivery in patients with sepsis. JAMA 1993, 269: 3024-3029.

6. Walsh TS, McArdle F, McLellan SA, Maciver C, Maginnis M, Prescott RJ, McClelland DB: Does the storage time of transfused red blood cells influence regional or global indexes of tissue oxygenation in anemic critically ill patients? Crit Care Med 2004, 32:364-371.

7. Dietrich KA, Conrad SA, Hebert CA, Levy GL, Romero MD: Cardiovascular and metabolic response to red blood cell transfu- sion in critically ill volume-resuscitated nonsurgical patients. Crit Care Med 1990, 18:940-944.

8. Lorente JA, Landin L, De Pablo R, Renes E, Rodriguez-Diaz R Liste D: Effects of blood transfusion on oxygen transport variables in severe sepsis. Crit Care Med 1993, 21:1312-1318.

9. Vamvakas EC, Carven $\mathrm{JH}$ : Length of storage of transfused red cells and postoperative morbidity in patients undergoing coronary artery bypass graft surgery. Transfusion 2000, 40: 101-109.

10. Hebert PC, Chin-Yee I, Fergusson D, Blajchman M, Martineau R, Clinch J, Olberg B: A pilot trial evaluating the clinical effects of prolonged storage of red cells. Anesth Analg 2005, 100:14331438.

11. Purdy FR, Tweeddale MG, Merrick PM: Association of mortality with age of blood transfused in septic ICU patients. Can J Anaesth 1997, 44:1256-1261.

12. Creteur J: Muscle $\mathrm{StO}_{2}$ in critically ill patients. Curr Opin Crit Care 2008, 14:361-366.

13. De Backer D, Creteur J, Silva E, Vincent JL: Effects of dopamine, norepinephrine, and epinephrine on the splanchnic circulation in septic shock: which is best? Crit Care Med 2003, 31:16591667.

14. Knaus WA, Draper EA, Wagner DP, Zimmerman JE: APACHE II: a severity of disease classification system. Crit Care Med $1985,13: 818-829$.

15. Vincent JL, Moreno R, Takala J, Willatts S, de Mendonca A, Bruining $H$, Reinhart CK, Suter PM, Thijs LG: The SOFA (Sepsisrelated Organ Failure Assessment) score to describe organ dysfunction/failure. On behalf of the Working Group on Sepsis-Related Problems of the European Society of Intensive Care Medicine. Intensive Care Med 1996, 22:707-710.

16. Skarda DE, Mulier KE, Myers DE, Taylor JH, Beilman GJ: Dynamic near-infrared spectroscopy measurements in patients with severe sepsis. Shock 2007, 27:348-353.

17. Mancini DM, Bolinger L, Li H, Kendrick K, Chance B, Wilson JR: Validation of near-infrared spectroscopy in humans. J Appl Physiol 1994, 77:2740-2747.

18. Sakr $Y$, Chierego $M$, Piagnerelli M, Verdant $C$, Dubois MJ, Koch M, Creteur J, Gullo A, Vincent JL, De Backer D: Microvascular response to red blood cell transfusion in patients with severe sepsis. Crit Care Med 2007, 35:1639-1644.

19. Piagnerelli M, Zouaoui BK, Brohee D, Vereerstraeten A, Piro P, Vincent $\mathrm{JL}$, Vanhaeverbeek M: Assessment of erythrocyte shape by flow cytometry techniques. J Clin Pathol 2007, 60: 549-554.

20. Friedlander $M H$, Simon $R$, Machiedo GW: The relationship of packed cell transfusion to red blood cell deformability in systemic inflammatory response syndrome patients. Shock 1998, 9:84-88.

21. Ho J, Sibbald WJ, Chin-Yee IH: Effects of storage on efficacy of red cell transfusion: when is it not safe? Crit Care Med 2003, 31:S687-S697.

22. Peck CC, Moore GL, Bolin RB: Adenine in blood preservation. Crit Rev Clin Lab Sci 1981, 13:173-212.

23. Raat NJ, Verhoeven AJ, Mik EG, Gouwerok CW, Verhaar R, Goedhart PT, de Korte D, Ince C: The effect of storage time of human red cells on intestinal microcirculatory oxygenation in a rat isovolemic exchange model. Crit Care Med 2005, 33:3945.

24. Lelubre C, Piagnerelli M, Vincent JL: Association between duration of storage of red blood cells and morbidity and mortality in adult patients: myth or reality? Transfusion 2009, 49:13841394.

25. Fernandes CJ, Jr, Akamine N, De Marco FV, De Souza JA, Lagudis $\mathrm{S}$, Knobel $\mathrm{E}$ : Red blood cell transfusion does not increase oxygen consumption in critically ill septic patients. Crit Care 2001, 5:362-367.

26. Leal-Noval SR, Munoz-Gomez M, Arellano-Orden V, Marin-Caballos A, Amaya-Villar R, Marin A, Puppo-Moreno A, Ferrandiz-Millon $\mathrm{C}$, Flores-Cordero JM, Murillo-Cabezas F: Impact of age of transfused blood on cerebral oxygenation in male patients with severe traumatic brain injury. Crit Care Med 2008, 36: 1290-1296.

27. Piagnerelli M, Silva E, Garrido A, Lambermont M, Knobel E, Vincent JL, De Backer D: Age of red blood cell transfusions in critically ill patients: comparison of two opposite transfusion policies. Intensive Care Med 2003, 29:660-661. 
28. Vallet B: Vascular reactivity and tissue oxygenation. Intensive Care Med 1998, 24:3-11.

29. De Backer D, Creteur J, Preiser JC, Dubois MJ, Vincent JL: Microvascular blood flow is altered in patients with sepsis. Am J Respir Crit Care Med 2002, 166:98-104.

30. De Backer D, Creteur J, Dubois MJ, Sakr Y, Vincent JL: Microvascular alterations in patients with acute severe heart failure and cardiogenic shock. Am Heart J 2004, 147:91-99.

31. Jhanji S, Lee C, Watson D, Hinds C, Pearse RM: Microvascular flow and tissue oxygenation after major abdominal surgery: association with post-operative complications. Intensive Care Med 2009, 35:671-677.

32. Creteur J, Carollo T, Soldati G, Buchele G, De Backer D, Vincent $\mathrm{JL}$ : The prognostic value of muscle $\mathrm{StO}_{2}$ in septic patients. Intensive Care Med 2007, 33:1549-1556.

33. Pohl U, Busse R: Hypoxia stimulates release of endotheliumderived relaxant factor. Am J Physiol 1989, 256:H1595-H1600.

34. Curtis SE, Vallet B, Winn MJ, Caufield JB, King CE, Chapler CK, Cain SM: Role of the vascular endothelium in $\mathrm{O}_{2}$ extraction during progressive ischemia in canine skeletal muscle. J Appl Physiol 1995, 79:1351-1360.

35. Greenberg B, Kishiyama S: Endothelium-dependent and -independent responses to severe hypoxia in rat pulmonary artery. Am J Physiol 1993, 265: H1 712-H1720.

36. Vallet B, Curtis SE, Winn MJ, King CE, Chapler CK, Cain SM: Hypoxic vasodilation does not require nitric oxide (EDRF/NO) synthesis. J Appl Physiol 1994, 76:1256-1261.

37. Landry DW, Oliver JA: The pathogenesis of vasodilatory shock. N Engl J Med 2001, 345:588-595.

38. Cosby K, Partovi KS, Crawford JH, Patel RP, Reiter CD, Martyr S, Yang BK, Waclawiw MA, Zalos G, Xu X, Huang KT, Shields H, Kim-Shapiro DB, Schechter AN, Cannon RO, III, Gladwin MT: Nitrite reduction to nitric oxide by deoxyhemoglobin vasodilates the human circulation. Nat Med 2003, 9:1498-1505.

39. Jia L, Bonaventura C, Bonaventura J, Stamler JS: S-nitrosohaemoglobin: a dynamic activity of blood involved in vascular control. Nature 1996, 380:221-226.

40. Ellsworth ML: The red blood cell as an oxygen sensor: what is the evidence? Acta Physiol Scand 2000, 168:551-559.

41. Crookes BA, Cohn SM, Bloch S, Amortegui J, Manning R, Li P, Proctor MS, Hallal A, Blackbourne LH, Benjamin R, Soffer D, Habib F, Schulman Cl, Duncan R, Proctor KG: Can near-infrared spectroscopy identify the severity of shock in trauma patients? J Trauma 2005, 58:806-813.

42. Desjardins C, Duling BR: Heparinase treatment suggests a role for the endothelial cell glycocalyx in regulation of capillary hematocrit. Am J Physiol 1990, 258:H647-H654.

43. Klitzman B, Duling BR: Microvascular hematocrit and red cell flow in resting and contracting striated muscle. Am J Physiol 1979, 237:H481-H490.

44. Sarelius IH, Duling BR: Direct measurement of microvessel hematocrit, red cell flux, velocity, and transit time. $A m$ J Physiol 1982, 243:H1018-H1026.

45. Doerschug KC, Delsing AS, Schmidt GA, Haynes WG: Impairments in microvascular reactivity are related to organ failure in human sepsis. Am J Physiol Heart Circ Physiol 2007, 293: H1065-H1071.

46. van Beekvelt MC, Borghuis MS, van Engelen BG, Wevers RA, Colier WN: Adipose tissue thickness affects in vivo quantitative near-IR spectroscopy in human skeletal muscle. Clin Sci (Lond) 2001, 101:21-28. 